\section{Microclimate and Scion Leaf Removal to Improve the Success of Grafted Tomato Seedlings}

\author{
Sarah A. Masterson ${ }^{1,4}$, Megan M. Kennelly ${ }^{2,5}$, Rhonda R. Janke ${ }^{1,6}$, \\ and Cary L. Rivard ${ }^{1,3,7,8}$
}

AdDITIONAL INDEX WORDs. tube grafting, splice grafting, rootstock, vapor pressure, best management practices

Summary. The utilization of grafted tomato (Solanum lycopersicum) plants in the United States shows significant promise, particularly as intensively managed production systems like high tunnels and greenhouses become more popular. However, the availability of grafted plants in the United States is currently a major barrier and a large portion of farmers who would like to use grafted plants would prefer to propagate their own. The objectives of this study were to determine how healing chamber design affects graft survival and microclimate, and to investigate how scion leaf and shoot removal affects graft survival in various healing chambers. Similar experiments were repeated at two locations in Kansas and a split-plot, randomized complete block design (RCBD) was used in each, with three and four replications being conducted over time at each of the locations. Five chamber treatments were tested including a negative control (none) as well as shadecloth alone, white vinyl mesh, polyethylene film and shadecloth, and polyethylene film with shadecloth and a cool-mist humidifier. No statistically significant effects of chamber design were seen on grafted plant success. However, microclimate data from the various healing chambers offer valuable data toward determining the best management practices for grafted plants. Shadecloth alone showed significant promise as this covering provided cooler temperatures during the afternoon when the healing chambers were prone to excessive heat buildup. Three tube-grafting methods were tested, including standard tube-grafted plants (no leaves removed), leaf removal $(\mathrm{LR})$ plants $(\approx 75 \%$ of the leaf surface area was removed from the scion), and shoot removal (SR) plants (the apical meristem and all true leaves were removed). The SR method did not affect graft survival, but the LR method increased grafting success from $78 \%$ to $84 \%$ and was significant as compared with the other methods $(P<0.05)$. The long-term goals of this work are to develop successful propagation systems that can be used by small-acreage growers with limited greenhouse facilities. The data presented here indicate that highhumidity healing chambers ( $>85 \%$ relative humidity) may not be necessary for tomato, and LR can increase the grafting success rate.

$\mathrm{H}$ erbaceous grafting is often applied to high-value vegetable crops such as watermelon (Citrullus lanatus), eggplant (Solanum melongena), and tomato worldwide for added vigor, stress tolerance, and disease resistance (Lee, 1994, 2003, 2007; Louws et al., 2010; Rivero et al., 2003). Although grafting may be very useful for tomato growers in the central region of the United States, there is limited availability of grafted plants propagated in the United States for commercial tomato fruit production. Results from a survey of fruit and vegetable growers at the 2014 Great Plains Growers Conference (St. Joseph, MO) showed that, of the 265 survey participants (65\% of whom are growing in high tunnels), $19 \%$ are using grafted plants to some degree, but an additional
$56 \%$ were interested in learning more on incorporating grafted plants into their production. Furthermore, 24\% of those surveyed indicated that they were not using grafted plants, but would like to, indicating the potential impact that increased plant availability could have on these farmers.

Large-scale nurseries in Canada have been selling grafted tomato plants in the United States (Kubota et al., 2008). However, meeting the low volume and/or specialized nature of orders that are needed for small-acreage and/or farmer'smarket growers may be difficult due to constraints associated with specialized scion/rootstock cultivar selection, timing requirements of the grower (e.g., multiple small shipments vs. one large shipment), seasonal variation and resulting planting date, shipping during periods of inclement weather, and issues associated with seed sanitation certification programs. Although large-scale grafting nurseries will most likely play a role in the production of grafted plants (Kubota et al., 2008), there still exists a strong need to advance knowledge related to propagation of grafted plants for small-acreage growers who wish to graft their own plants (1000-15,000 plants annually). By grafting plants on the farm, growers can maintain control of their propagation systems (e.g., plant delivery date, need for specialty scion or rootstock cultivars, ease of providing plants for succession plantings, organic certification, etc.) and could potentially increase on-farm revenue when plants are sold to nearby farmers and/or gardeners. In the 2014 survey at the Great Plains Growers Conference mentioned above $(\mathrm{n}=265), 47 \%$ of respondents indicated that they would prefer to grow their own grafted plants, whereas $25 \%$ indicated they would prefer to purchase grafted plants. An additional $28 \%$ were not interested in growing or purchasing grafted plants. These data highlight the potential impact that development of accessible propagation systems could have at overcoming plant availability, which is a significant barrier in the adoption of grafting in the United States.

The most popular grafting method for tomato is the tube-grafting technique (also known as splice grafting or Japanese top grafting) due to its efficiency and simplicity (Oda, 1995). This process (Bumgarner and Kleinhenz, 2014; Rivard and Louws,

\begin{tabular}{llll}
\hline $\begin{array}{l}\text { Units } \\
\text { To convert U.S. to SI, } \\
\text { multiply by }\end{array}$ & U.S. unit & SI unit & $\begin{array}{l}\text { To convert SI to U.S., } \\
\text { multiply by }\end{array}$ \\
\hline 0.3048 & $\mathrm{ft}$ & $\mathrm{m}$ & 3.2808 \\
2.54 & inch $(\mathrm{es})$ & $\mathrm{cm}$ & 0.3937 \\
25.4 & inch $(\mathrm{es})$ & $\mathrm{mm}$ & 0.0394 \\
0.0254 & $\mathrm{mil}$ & $\mathrm{mm}$ & 39.3701 \\
33.9057 & $\mathrm{oz} / \mathrm{yard}^{2}$ & $\mathrm{~g} \cdot \mathrm{m}^{-2}$ & 0.0295 \\
$\left({ }^{\circ} \mathrm{F}-32\right) \div 1.8$ & ${ }^{\circ} \mathrm{F}$ & ${ }^{\circ} \mathrm{C}$ & $\left({ }^{\circ} \mathrm{C} \times 1.8\right)+32$
\end{tabular}


2011) requires that the rootstock and scion (with 1.5- to $2-\mathrm{mm}$ stem diameters) are cut at $\approx 60^{\circ}$ to $75^{\circ}$ angles (Bausher, 2013), held together with a silicon grafting clip, then placed in an environment ("healing chamber") with high humidity and low light to promote a connection between the vascular tissues and prevent scion wilt (Oda, 2007).

Healing chamber management can be difficult. In particular, overheating of healing chambers inside of greenhouses has been problematic for grafted tomato transplant growers in the United States that are experimenting with grafting (C.L. Rivard, unpublished data). Not only do healing chambers require increased labor and management, but they also add to the overall cost of producing a grafted transplant as it requires additional materials and laboraccounting for $6.1 \%$ to $6.5 \%$ of the additional costs encountered when producing grafted tomato plants (Rivard et al., 2010). On the basis of industry and extension technical publications, the current recommended temperature range for healing chambers is 28 to $29^{\circ} \mathrm{C}$, and the recommended range for relative humidity is $85 \%$ to $100 \%$ (De Ruiter Seeds, 2006; Rivard and Louws, 2011). Johnson and Miles (2011) noted that tomato might be more tolerant of higher temperature and variable relative humidity (and thereby require less maintenance) than other horticultural

\footnotetext{
$\overline{\text { Funding was provided by the graduate student grants }}$ from the CERES Trust Research Initiative and the North Central Region Sustainable Agriculture Research and Education (NCR-SARE) program (GNCl2-162).

We sincerely thank the Olathe Horticulture Research and Extension Center, as well as Lea Westervelt and the KSU-Manhattan greenhouse staff. We also thank Mark Gawron, Annette Finkeldei, and Vicente Mascote for technical support.

Mention of a trademark, proprietary product, or vendor does not constitute a guarantee or warranty of the product and does not imply its approval to the exclusion of other products or vendors that also may be suitable.

${ }^{1}$ Department of Horticulture, Forestry, and Recreation Resources, Kansas State University, Manhattan, KS 66506

${ }^{2}$ Department of Plant Pathology, Kansas State University, Manhattan, KS 66506

${ }^{3}$ Kansas State University Olathe Horticulture Research and Extension Center, Olathe, KS 66061

${ }^{4}$ Graduate Research Assistant

${ }^{5}$ Associate Professor

${ }^{6}$ Professor

${ }^{7}$ Assistant Professor
}

${ }^{8}$ Corresponding author. E-mail: crivard@ksu.edu. crops such as watermelon. However, systematic experiments have not been published that quantify the effects of temperature and humidity on graft survival. Furthermore, the successful adoption of grafted propagation by small-scale tomato growers requires simple effective techniques that work within propagation facilities that have limited climate control and/or lighting available.

The function of the healing chamber is to reduce water stress on the scion tissue so that it can survive while the graft union fuses. In addition to modifications to the healing chamber, removal of leaf and/or tissue may prevent excessive evapotranspiration and therefore reduce or eliminate the need for microclimate management. The leaves probably play an important role in graft union formation due to their ability to provide photosynthate during the formation of the graft union. Leaf removal is recommended as a best management practice for the cleft and splice method (Bumgarner and Kleinhenz, 2014). Reducing water stress on the scion tissue by removing leaf area may reduce or eliminate reliance on the healing chamber, which could potentially facilitate more grafting success for a propagator with limited facilities.

In addition to reducing water stress, the removal of the entire scion meristem could expedite the process of growing a plant with two "leaders." Two on-farm case studies from North Carolina and Pennsylvania were published by Rivard et al. (2010) to determine the estimated production costs for grafted tomato plants. The production model used by a commercial propagator in Pennsylvania included removal of the meristem $10 \mathrm{~d}$ postgrafting to encourage two "leaders" for vertical trellising. This practice is common for greenhouse production and high tunnel production of indeterminate cultivars with grafted plants (Besri, 2003; Kubota et al., 2008). By removing the meristem after the grafted plant has been healed, additional regrowth time is required, and this can set back planting in the field/greenhouse 10 to $14 \mathrm{~d}$ and/or slow early growth. The removal of the meristem during the grafting procedure could result in a grafted plant with two leaders, and would reduce the added time for regrowth posthealing. It would also potentially help reduce water loss by the scion, similarly to LR, which could facilitate less intensively managed healing chambers.

Clearly, there exists a strong need to determine not only environmental factors related to healing chambers, but also information related to LR and SR to help facilitate the development of successful propagation systems for small-acreage tomato growers. Therefore, the overall goals of this study were to 1 ) determine if healing chamber design (supplemental humidity and covering) affects graft survival, 2) describe how healing chamber design affects the healing chamber microclimate, and 3 ) investigate if scion shoot and/or LR affect graft survival in various healing chamber environments.

\section{Materials and methods}

Two similar greenhouse experiments were conducted in Spring 2013 at two different locations in Kansas: Throckmorton Plant Sciences Center at Kansas State University (KSU) in Manhattan (lat. $39.192980^{\circ} \mathrm{N}$, long. $96.585469^{\circ} \mathrm{W}$ ) and the KSU Olathe Horticulture Research and Extension Center (OHREC) located in Olathe (lat. $38.884347^{\circ} \mathrm{N}$, long. $\left.94.993426^{\circ} \mathrm{W}\right)$. All experiments were conducted in a split-plot RCBD and were replicated over time. There were three replications used in the experiment at Manhattan and four replications in the experiment performed at OHREC. The replications were conducted over time to reduce labor and healing chamber space needs during grafting. Individual replicates (batches) were seeded every 1-2 weeks at each location and all seeding was performed from 22 Jan. to 15 Mar. The main plot factor was chamber design (described below), with four chamber designs tested in Manhattan and an additional one tested at OHREC. Microclimate data from the "none" chamber provided replicated relative humidity and temperature data that accurately depicts the greenhouse environment. The subplot factor was grafting method, with standard and SR techniques tested in Manhattan; and standard, SR, and LR tested at OHREC. Those methods are described in the Grafting Methods section. During preliminary studies, plants grafted 
with the SR technique were susceptible to shading by standard-grafted plants. Therefore, the plants were arranged in blocks within each chamber with each subplot consisting of 150 plants and 100 plants in Manhattan and OHREC, respectively.

Grafting METHODs. A commercial scion/nongrafted cultivar, Cherokee Purple (Johnny's Selected Seeds, Winslow, ME) was used for the experiment and all plants were self-grafted by grafting scions back onto their original root system. Selfgrafting allows that the plants experience the grafting process without added variables such as genetic incompatibility and/or inconsistent rootstock and scion angles during the grafting procedure. Therefore, by using the self-grafting method, outside bias is reduced to determine the effect of LR and postgrafting microclimate management alone. The standard tube-grafting method for tomato was used (Rivard and Louws, 2011). For all grafting treatments, rootstock and scion seedling stems were severed below the cotyledons and then held together using a $2.0-\mathrm{mm}$ silicon clip (Johnny's Selected Seeds). For the standard treatment, no leaves were removed from the scion. The SR treatment consisted of removing the entire apical meristem and all leaves from the scion at the time of grafting $1-2 \mathrm{~cm}$ above the cotyledon leaf nodes, leaving stem and two cotyledon leaves (with axillary buds for two leaders to develop). In the $\mathrm{LR}$ treatment, $\approx 75 \%$ of the leaf area tissue was removed by cutting the stipules of fully expanded leaves and small leaflets with scissors, and some leaf material was left attached. To achieve this, the entire scion was pulled upward from the stem and all leaves were cut across the top leaving behind the apical meristem in addition to $\approx 25 \%$ of the remaining leaf material. Plants were grafted on-site at each location with trained personnel (three to four individual grafters). Each person performing the grafting process grafted the same proportion of plants for each chamber and grafted an equal number of plants within each subplot treatment (grafting method) at both locations. This approach was used to reduce the effect of bias across individuals on the treatments. Grafted plant survival data were observed and recorded $14 \mathrm{~d}$ after grafting for all replications.

Healing CHAmber design. Four chamber designs ("humidifier," "plastic," "shade," and "perforated plastic") and a no-chamber control ("none") were tested in Olathe. All treatments except the one that used perforated plastic were tested in Manhattan. The humidifier chamber was built to specifications as described in Rivard and Louws (2011), and is typically recommended for small-scale propagators grafting $<5000$ plants per batch. It included a 4-mil polyethylene film covering that encompassed the entire chamber as well as $55 \%$ shadecloth across the top and a cool-mist humidifier (SU-2000; Sunpentown, City of Industry, CA) located outside of the chamber. The humidifier delivered water vapor via poly vinyl chloride tubing (2-inch diameter). The plastic chamber was identical to the humidifier chamber except that a humidifier was not used. In both the humidifier and plastic treatments, $\approx 1$ inch of water was added and maintained on the chamber floor for additional humidity. The shadecloth chamber was covered with $55 \%$ shadecloth and lacked a polyethylene film covering and floor, standing water, or a humidifier. The perforated plastic chamber was covered with mesh vinyl tarp that provided $70 \%$ shade ( $10 \mathrm{oz} /$ yard $^{2}$; Billboard Tarps, Minneapolis, MN), and was evaluated only at the Olathe location. Similar to the shade chamber, no other polyethylene film was used for a covering and this chamber design had no floor or humidifier. The "none" chamber was open to the greenhouse conditions (described below) with no additional microclimate modification. For the humidifier and plastic treatments, trays of grafted plants need to be placed on top of upside-down propagation (web) trays to elevate grafted plants two inches above the floor of the chamber to keep them out of water. Therefore, grafted plants were placed on upsidedown trays in all other healing chamber treatments within the experiment to reduce bias that may be caused by tray elevation within the greenhouse. All healing chambers were built to dimensions of $3 \times 4 \times 2 \mathrm{ft}$ using composite (plastic) decking boards with steel wire hoops for holding the polyethylene film and/or shadecloth off of the plants (Fig. 1). All chambers included a standardized frame with
1 inch $\times 5.5$-inch composite decking boards whereby the board sat on its edge to create a 5.5-inch sidewall for the chamber. Holes were drilled vertically into the top edge of the board to accommodate insertion of the steel wire resulting in a hoop that served as the frame. Nine-gauge wire was cut to equal lengths and inserted so as to permit a small chamber $2 \mathrm{ft}$ tall at the peak (Fig. 1).

HEALING CHAMBER MANAGEMENT. The day of grafting was considered Day 0 for both locations and during each replication. On Day 0, 150 plants from each grafting method were placed in each healing chamber. In Manhattan, 150 standardgrafted and 150 SR-grafted plants were placed in each of the four chamber designs, for a total of 1200 plants. In Olathe, 100 standard grafted, 100 SR, and $100 \mathrm{LR}$ were placed in each of the five chambers for a total of 1500 plants. The humidifier and plastic treatments employed full shadecloth coverings and were briefly vented twice daily until Day 5, when the shadecloth was removed to provide partial light exposure (see description of greenhouse conditions below). The humidifier was turned off on Day 7. All plants were removed from the chambers on Day 8 and watered daily.

KSU greenhouse, Manhattan, KS. The greenhouse in Manhattan consisted of a glass covering with typical environmental controls for a university research greenhouse including forced air heating and cooling pads. A layer of $55 \%$ shadecloth was suspended above the healing chambers to reduce light exposure that could lead to excessive temperatures within the healing chambers. This is typically recommended for grafting tomato in areas with high temperatures (Bumgarner and Kleinhenz, 2014; Oda, 2007; Rivard and Louws, 2011). Temperature and relative humidity of the greenhouse environment is represented below by the "none" treatment and therefore can be used for background information related to the ambient climate in the greenhouse. Replication 1 was seeded on 22 Jan. 2013 and subsequently transplanted into 50-cell trays on $8 \mathrm{Feb}$. Grafting of the first replication took place on 23 Feb. The final survival count occurred on 9 Mar. 2013. Replication 2 was seeded on 31 Jan., transplanted on 15 Feb., and 


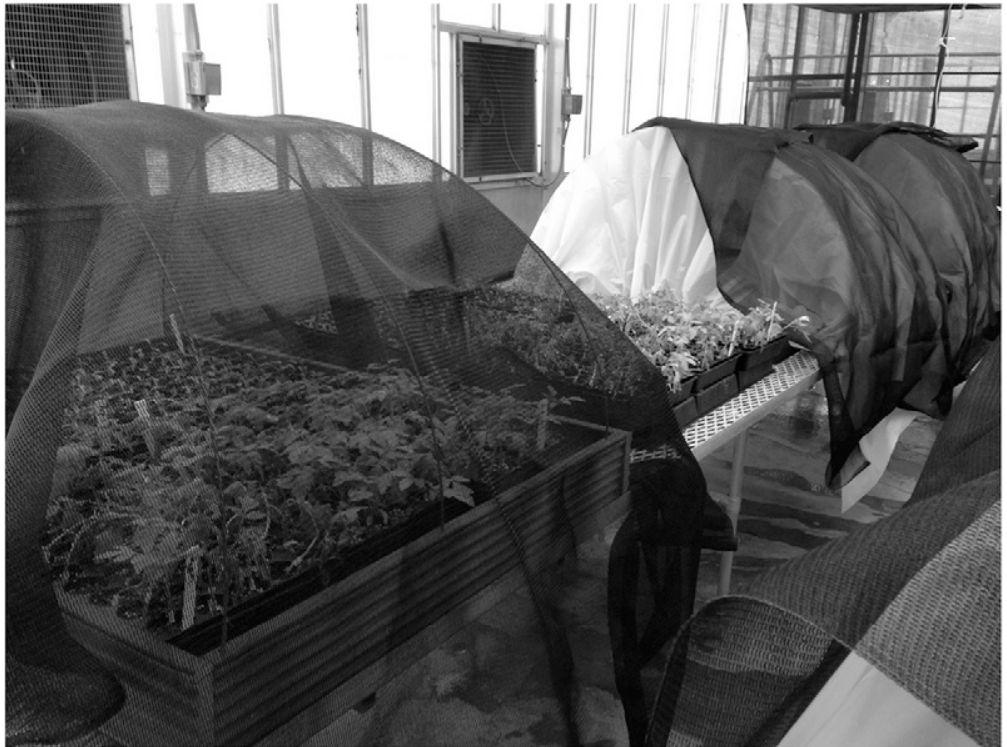

Fig. 1. Healing chambers during the first replication at the Kansas State University, Manhattan greenhouse. Healing chamber frames were assembled from plastic lumber and wire. From left to right: a "shadecloth" treatment, a "none" treatment, a "plastic" treatment, and a "humidifier" treatment. Subplots (grafting method) were randomized within the main plot (healing chamber design) treatments and the standard and shoot-removal grafting method can be seen in the foreground and background, respectively.

grafted on 1 Mar. Replication 3 was seeded on 23 Feb., transplanted on 13 Mar., and grafted on 28 Mar. The final survival count for replication 2 and 3 occurred on 15 Mar. and 11 Apr., respectively.

OHREC GREENHOUSE, Olathe, KS. The greenhouse experiments at OHREC were performed in a quonset-style greenhouse that had $10-\mathrm{mm}$ twin-wall polycarbonate walls and a typical commercial greenhouse polyethylene-film roof (6 mils). Similar to the Manhattan greenhouse, forced air heating and cooling pads were in use. Replication 1 was seeded on 1 Feb. 2013 and transplanted on 15 Feb. Grafting of replication 1 occurred on 1 Mar. Replication 2 was seeded on 22 Feb., transplanted on 1 Mar., and grafted on 15 Mar. Replication 3 was seeded on 1 Mar., transplanted on 15 Mar., and grafted on 25 Mar. Replication 4 was seeded on 15 Mar., transplanted on 29 Mar., and grafted on 8 Apr. Similar to the other location, grafted plant survival data were recorded $14 \mathrm{~d}$ after grafting for each replication, which was on 15 and 29 Mar. and 8 and 22 Apr.

Microclimate data COLlection AND ANALYSIS. Environmental conditions within each chamber were monitored via temperature and relative humidity dataloggers (EL-USB-2LCD; Lascar Electronics, Erie, PA). Similarly, the microclimate data recorded for the plants with no chamber (negative control) constitutes replicated environmental data for the greenhouse environment. One datalogger per treatment was placed among the seedlings in the center of each chamber and temperature and relative humidity data were recorded at 30 -min intervals. The dataloggers were activated once all seedlings were placed within the chambers and synced by using a delayed start function to ensure that they were collecting data at the same time(s). Temperature and relative humidity from Day $0-10$ averages, minimums, and maximums were analyzed using analysis of variance (PlotIt; Scientific Programming Enterprises, Haslett, MI). When significant treatment effects were identified, a mean separation test was carried out using an Fischer's protected LSD test. To observe daily fluctuation in temperature and relative humidity for each of the healing chamber treatments, the average values of these two parameters, during the first full day after grafting (Day l) for each replication, were calculated (Figs. 2 and $3)$. These data represent daily fluctuations in microclimate as they relate to the healing chamber design.
SurVival RATINGS AND DATA ANALYSIS. On Day 14, plant survival was observed. All data were analyzed independently as there were additional main and subplot treatments in the experiment performed at OHREC. Therefore, statistical interaction between the grafting method treatments and the location could not be identified. All survival data were analyzed in SPSS (IBM, Armonk, NY) and showed no significant deviation from variance homogeneity; in addition, skewness and kurtosis statistics concluded that survival data were about normal. Mean survival was calculated and analyzed using analysis of variance (PlotIt). When significant treatment effects were identified, a mean separation test was carried out using an Fischer's protected LSD test.

\section{Results}

EFFECT OF CHAMBER DESIGN ON RELATIVE HUMIDITY AND TEMPERATURE. Relative humidity was highly impacted by healing chamber design in both studies and the average relative humidity ranged from $48.4 \%$ to 91.3\% among all the treatments at both locations (Table 1 ). At the Manhattan location, the plastic and humidifier chambers showed a significant increase $(P<0.05)$ in minimum and average relative humidity compared with the "none" and shade treatments (Table 1). There were no significant differences in maximum relative humidity in Manhattan. High relative humidity is common in greenhouses of this type on cloudy days and one or two particularly humid days make it difficult to assess the impact of maximum relative humidity on grafting success. At OHREC, comparable results were observed, where the plastic and humidifier treatments had significantly greater average, minimum, and maximum relative humidity than the other three treatments $(P<0.05)$. In Manhattan, the addition of the cool-mist humidifier to the chamber increased the average relative humidity from $78.9 \%$ to $85.1 \%$, but this difference was not significant. However, at OHREC, the average relative humidity in the plastic chamber was $85.3 \%$, whereas it was $91.3 \%$ in the humidifier chamber and was statistically significant $(P<0.05$; Table 1$)$. Average and minimum and maximum temperatures for both locations are shown in Table 2. There was no 

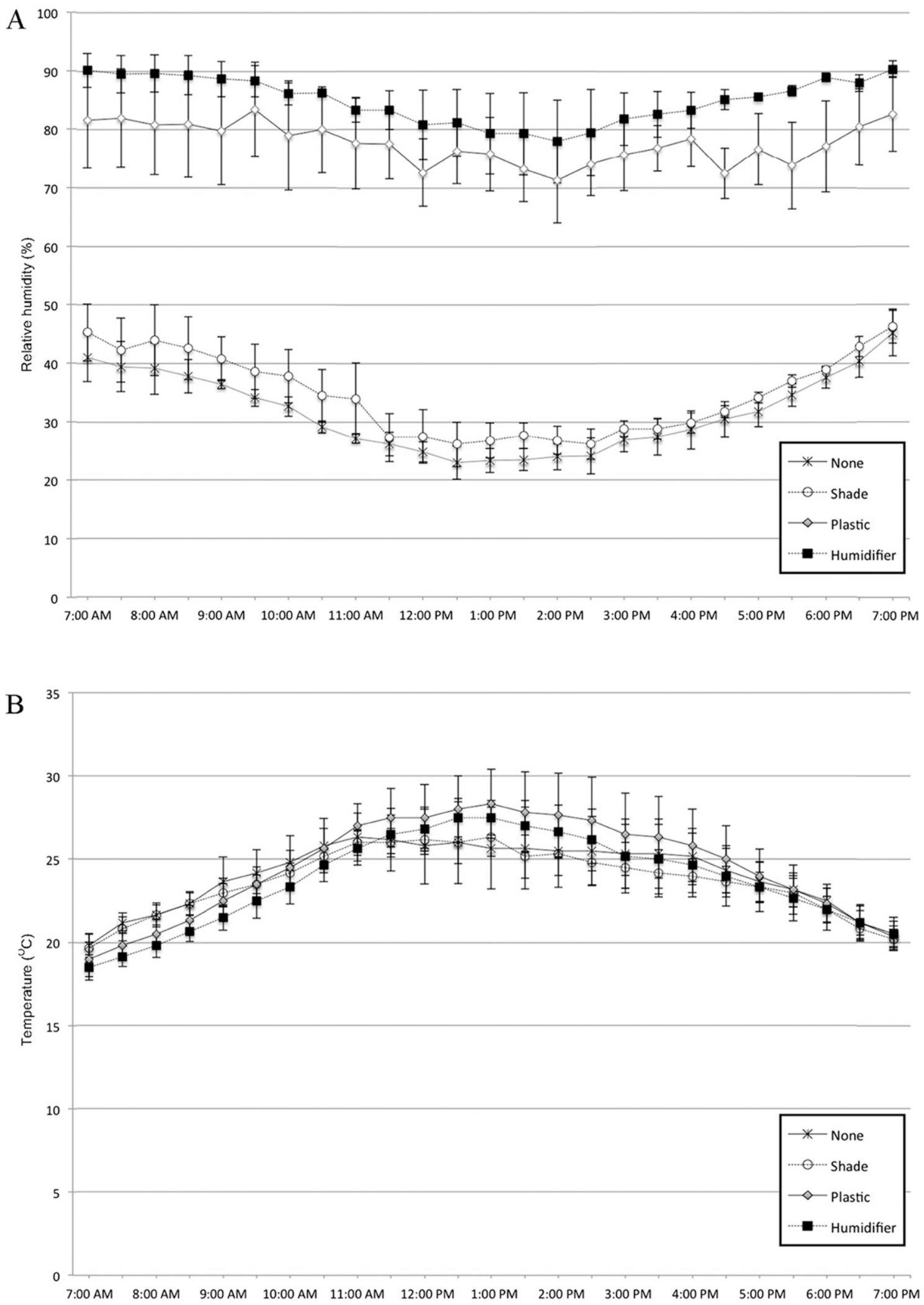

Fig. 2. Average (A) relative humidity and (B) temperature within different chamber treatments at a greenhouse in Manhattan, KS, during a 12-h period (7:00 AM to 7:00 PM) following the initial grafting day (Day 1). Data were recorded with digital dataloggers every $30 \mathrm{~min}$ (one datalogger per treatment) and averaged across three replications over time. Vertical bars represent SE; $\left(1.8 \times{ }^{\circ} \mathrm{C}\right)+32={ }^{\circ} \mathrm{F}$. 


\section{Research Reports}
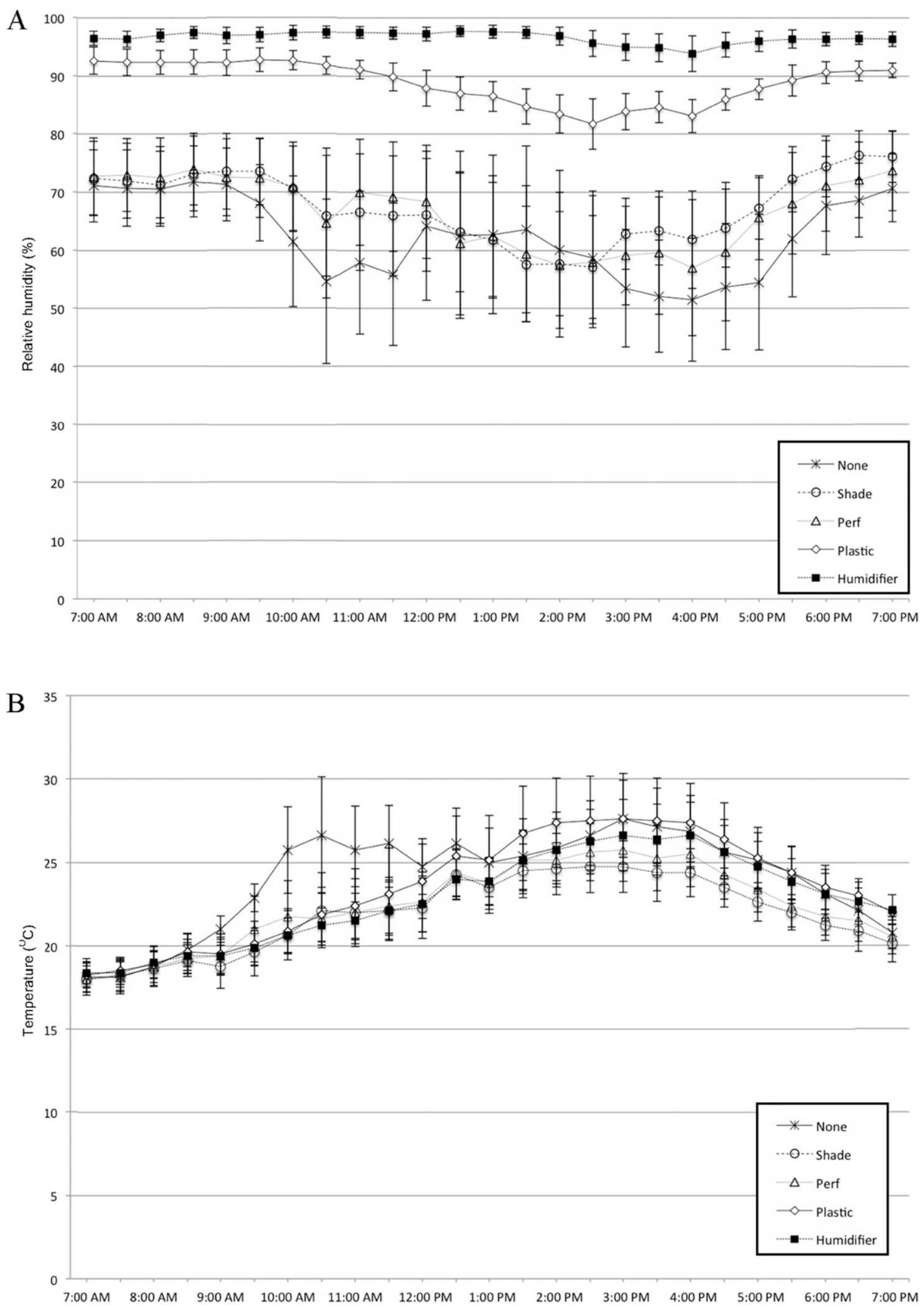

Fig. 3. Average recordings of (A) relative humidity and (B) temperature within different chamber treatments at the greenhouse in Olathe, $\mathrm{KS}$, during a 12-h period (7:00 AM to 7:00 PM) following the initial grafting day (Day 1). Data were recorded with digital dataloggers every $30 \mathrm{~min}$ (one datalogger per treatment) and averaged across four replications over time. Vertical bars represent SE; $\left(1.8 \times{ }^{\circ} \mathrm{C}\right)+32={ }^{\circ} \mathrm{F}$. 
Table 1. Effects of chamber design on daily average, minimum, and maximum relative humidity for grafted tomato seedlings from Day 0 to Day 10 at Manhattan, KS, and Olathe, KS, greenhouse studies in 2013.

\begin{tabular}{|c|c|c|c|}
\hline \multirow[b]{2}{*}{ Treatment $^{\mathrm{z}}$} & \multicolumn{3}{|c|}{ Relative humidity (\%) } \\
\hline & Avg & Minimum & Maximum \\
\hline \multicolumn{4}{|c|}{ Manhattan $^{\mathrm{y}}$} \\
\hline None & $48.4 \mathrm{a}$ & $17.2 \mathrm{a}$ & 89.8 \\
\hline Shade & $50.5 \mathrm{a}$ & $19.7 \mathrm{a}$ & 94.3 \\
\hline Plastic & $78.9 \mathrm{~b}$ & $35.3 \mathrm{~b}$ & 99.3 \\
\hline Humidifier & $85.1 \mathrm{~b}$ & $37.2 \mathrm{~b}$ & 98.5 \\
\hline$P$ value ${ }^{w}$ & $<0.001$ & 0.044 & NS \\
\hline \multicolumn{4}{|c|}{ Olathe $^{\mathrm{x}}$} \\
\hline None & $66.8 \mathrm{a}$ & $25.3 \mathrm{a}$ & $91.8 \mathrm{a}$ \\
\hline Shade & $69.2 \mathrm{a}$ & $26.9 \mathrm{a}$ & $93.3 \mathrm{a}$ \\
\hline Perforated plastic & $69.2 \mathrm{a}$ & $25.5 \mathrm{a}$ & $93.3 \mathrm{a}$ \\
\hline Plastic & $85.3 \mathrm{~b}$ & $33.0 \mathrm{~b}$ & $97.6 \mathrm{~b}$ \\
\hline Humidifier & $91.3 \mathrm{c}$ & $37.5 \mathrm{c}$ & $99.8 \mathrm{c}$ \\
\hline$P$ value ${ }^{\mathrm{w}}$ & $<0.001$ & 0.002 & $<0.001$ \\
\hline
\end{tabular}

z"None" chamber is completely open to greenhouse conditions with no environmental controls other than the upside-down web trays to elevate the trays off of the bench. "Shade" chamber was covered with $55 \%$ shadecloth and had no humidity modifications. "Humidifier" and "plastic" treatments employed 4 -mil $(0.1 \mathrm{~mm})$ plastic covering that encompassed the entire chamber as well as $\mathbf{5 5 \%}$ shadecloth across the top; both were vented daily until Day 5, when the cloth was removed and partial shade was applied. These treatments also had 1 inch $(2.5 \mathrm{~cm})$ of water in the bottom of the chamber. "Humidifier" chamber used a cool-mist humidifier, which was removed from the treatment on Day 7. "Perforated plastic" was similar in conceptual design to the "shadecloth" treatment and was only covered with a $70 \%$ shade white mesh vinyl tarp and no humidifier was used.

yThrockmorton Plant Sciences Center at Kansas State University in Manhattan.

'Kansas State University Olathe Horticulture Research and Extension Center in Olathe.

"Values followed by the same letter are not significantly different according to a protected least significant difference test $(\alpha=0.05)$.

Table 2. Effects of chamber design on daily average, minimum, and maximum temperature for grafted tomato seedlings from Day 0 to Day 10 at Manhattan, KS and Olathe, KS greenhouse studies in 2013.

\begin{tabular}{|c|c|c|c|}
\hline \multirow[b]{2}{*}{ Treatment $^{\mathrm{z}}$} & \multicolumn{3}{|c|}{ Temperature $\left({ }^{\circ} \mathbf{C}\right)^{\mathrm{y}}$} \\
\hline & Avg & Minimum & Maximum \\
\hline \multicolumn{4}{|c|}{ Manhattan $^{\mathrm{x}}$} \\
\hline None & 20.8 & 14.2 & 28.8 \\
\hline Shade & 20.4 & 13.5 & 27.3 \\
\hline Plastic & 20.5 & 14.2 & 29.5 \\
\hline Humidifier & 20.4 & 14.2 & 29.7 \\
\hline$P$ value $^{\mathrm{v}}$ & NS & NS & NS \\
\hline \multicolumn{4}{|c|}{ Olathe $^{\text {w }}$} \\
\hline None & $20.8 \mathrm{~b}$ & 10.5 & 35.3 \\
\hline Shade & $19.8 \mathrm{a}$ & 10.9 & 31.6 \\
\hline Perforated plastic & $20.0 \mathrm{a}$ & 10.8 & 32.6 \\
\hline Plastic & $20.5 \mathrm{~b}$ & 10.4 & 35.8 \\
\hline Humidifier & $20.5 \mathrm{~b}$ & 10.4 & 35.1 \\
\hline$P$ value $^{\mathrm{v}}$ & 0.034 & NS & NS \\
\hline
\end{tabular}

"None" chamber is completely open to greenhouse conditions with no environmental controls other than the upside-down web trays to elevate the trays off of the bench. "Shade" chamber was covered with $55 \%$ shadecloth and had no humidity modifications. "Humidifier" and "plastic" treatments employed 4-mil $(0.1 \mathrm{~mm})$ plastic covering that encompassed the entire chamber as well as $55 \%$ shadecloth across the top; both were vented daily until Day 5, when the cloth was removed and partial shade was applied. These treatments also had 1 inch $(2.5 \mathrm{~cm})$ of water in the bottom of the chamber. "Humidifier" chamber used a cool-mist humidifier, which was removed from the treatment on Day 7. "Perforated plastic" was similar in conceptual design to the "shadecloth" treatment and was only covered with a $70 \%$ shade white mesh vinyl tarp and no humidifier was used.

$\mathrm{y}\left(1.8 \times{ }^{\circ} \mathrm{C}\right)+32={ }^{\circ} \mathrm{F}$

xThrockmorton Plant Sciences Center at Kansas State University in Manhattan.

"Kansas State University Olathe Horticulture Research and Extension Center in Olathe, KS.

"Values followed by the same letter are not significantly different according to a protected least significant difference test $(\alpha=0.05)$.

statistical separation for these data with the exception of average temperature at OHREC $(P<0.05$; Table 2$)$. At the OHREC greenhouse, the: "none," plastic, and humidifier chambers all had significantly greater average temperatures than the shade and perforated plastic treatments but they were still all within $1{ }^{\circ} \mathrm{C}(P<0.05)$. However, it should be noted that the shade chamber had the lowest maximum temperatures.

Daily fluctuations in both temperature and relative humidity were observed in all chambers at both greenhouses, as shown in Figs. 2 and 3 , which represent the mean value of all replications for each site over a 12-h period on Day l, postgrafting. It is interesting to note that the relative humidity, particularly for the "none" and shade treatments were very different across the two locations. In Manhattan, the approximate range of the average relative humidity was from $20 \%$ to $50 \%$ (Fig. 2 ), whereas at OHREC, the average relative humidity was between $50 \%$ and $80 \%$ in the "none" and shade treatments (Fig. 3). The ambient environment in the greenhouse itself clearly played a role in defining the microclimate in the shade chamber. The shade chamber also showed a trend of keeping the plants cooler after 1:00 PM, although this trend was not statistically significant (Figs. 2 and 3 ).

Percent grafting survival. In both studies, no significant interactions were observed between the treatment main effects and grafting technique subeffects. In Table 3 , plant survival ranged from $91 \%$ to $95 \%$ and no significant differences were observed between healing chamber treatments and grafting technique (Table 3). Similar to the experiment in Manhattan, healing chamber treatments had no effect on graft survival in the Olathe study (Table 4), which ranged from $77 \%$ to $87 \%$ across the different chamber types. However, the main effects of grafting method showed that plants grafted with the LR technique had higher survival than the other grafting methods at $84 \%(P<0.05$; Table 4$)$ across all the chamber types.

\section{Discussion}

At both locations, weather patterns and the resulting growing conditions were ideal for grafting as late winter and early spring weather in the central United States provide ample cloud cover to prevent healing chambers from overheating in the greenhouse. This may have been a factor that led to high grafting success and little separation of the treatments 
Table 3. Main effects of healing chamber design and grafting technique upon mean grafted tomato plant survival in a greenhouse study in Manhattan, KS.

\begin{tabular}{|c|c|}
\hline Treatment $^{\mathrm{z}}$ & Survival (\%) \\
\hline \multicolumn{2}{|c|}{ Chamber design $^{x}$} \\
\hline None & 91 \\
\hline Shade & 94 \\
\hline Plastic & 95 \\
\hline Humidifier & 94 \\
\hline $\operatorname{LSD}(0.05)$ & 4.7 \\
\hline \multicolumn{2}{|c|}{ Grafting method ${ }^{w}$} \\
\hline Standard & 94 \\
\hline Shoot removal & 93 \\
\hline $\operatorname{LSD}(0.05)$ & 4.2 \\
\hline
\end{tabular}

${ }^{\mathrm{z}}$ Main effects of a split-plot design are reported here. Healing chamber design was the main plot and grafting method was the subplot. Values followed by the same letter are not significantly different according to a protected least significant difference (LSD) test $(\alpha=0.05)$. The calculated LSD value is shown.

${ }^{y}$ Mean percent survival of self-grafted 'Cherokee Purple' tomato plants $14 \mathrm{~d}$ postgrafting.

"None" chamber is completely open to greenhouse conditions with no environmental controls other than the upside-down web trays to elevate the trays off of the bench. "Shade" chamber was covered with $55 \%$ shadecloth with no humidity modifications. "Humidifier" and "plastic" treatments employed 4-mil $(0.1 \mathrm{~mm})$ plastic covering that encompassed the entire chamber as well as $55 \%$ shadecloth across the top; both were vented daily until Day 5 , when the cloth was removed and partial shade was applied. "Humidifier" chamber used a cool-mist humidifier, which was removed from the treatment on Day 7.

"In the standard tube-grafting method, no leaves were removed during the grafting procedure. In the shootremoval method, all true leaves and apical meristem of scion tissue was removed upon grafting leaving behind the stem and two cotyledon leaves.

with regard to temperature. Unfortunately, incoming light measurements were not recorded as equipment was not available. Future studies of this type would benefit from this data as it could be correlated with healing chamber temperature fluctuations and overall grafting success. The labor requirements needed for grafting and collecting data from 1200-1500 plants per replication are high in addition to the number of healing chambers and space required. Therefore, replication over time and in 1-2 week increments (per replication) was necessary. In the experiment conducted in Manhattan, the three replicates were sown across a period of 4 weeks (22 Jan. to 23 Feb.), and in the OHREC experiment, the four replicates were planted across a 6-week period (1 Feb. to 15 Mar.). It should also be noted that this is a typical timeline for propagating grafted plants in the central United States and therefore reflects what
Table 4. Main effects of healing chamber design and grafting technique upon mean grafted tomato plant survival in a greenhouse study at Olathe, KS.

\begin{tabular}{|c|c|}
\hline Treatment $^{\mathrm{z}}$ & Survival (\%) \\
\hline \multicolumn{2}{|c|}{ Chamber design $^{x}$} \\
\hline None & 81 \\
\hline Shade & 78 \\
\hline Perforated plastic & 77 \\
\hline Plastic & 78 \\
\hline Humidifier & 87 \\
\hline LSD $(0.05)$ & 9.7 \\
\hline \multicolumn{2}{|c|}{ Grafting method ${ }^{\mathrm{w}}$} \\
\hline Standard & $78 \mathrm{a}$ \\
\hline Shoot removal & 79 a \\
\hline Leaf removal & $84 \mathrm{~b}$ \\
\hline LSD $(0.05)$ & 5.1 \\
\hline
\end{tabular}

${ }^{2}$ Main effects of a split-plot design are reported here. Healing chamber design was the main plot and grafting method was the subplot. Values followed by the same letter are not significantly different according to a protected least significant difference (LSD) test $(\alpha=0.05)$. The calculated LSD value is shown.

${ }^{y}$ Mean percent survival of self-grafted 'Cherokee Purple' tomato plants $14 \mathrm{~d}$ postgrafting.

"None" chamber is completely open to greenhouse conditions with no environmental controls other than the upside-down web trays to elevate the trays off of the bench. "Shade" chamber was covered with 55\% shadecloth with no humidity modifications. "Perforated plastic" was similar in conceptual design to the "shade" treatment and was only covered with a $70 \%$ shade white mesh vinyl tarp and no humidifier was used. "Humidifier" and "plastic" treatments employed 4 -mil $(0.1 \mathrm{~mm})$ plastic covering that encompassed the entire chamber as well as $55 \%$ shadecloth across the top; both were vented daily until Day 5, when the cloth was removed and partial shade was applied. "Humidifier" chamber used a coolmist humidifier, which was removed from the treatment on Day 7 .

wIn the standard tube-grafting method, no leaves were removed during the grafting procedure. In the shootremoval method, all true leaves and apical meristem of scion tissue was removed upon grafting leaving behind the stem and two cotyledon leaves. In the leafremoval method, mature leaves and partial emerging leaflets $(\approx 75 \%$ of total leaf area) of scion tissue were removed upon grafting.

a propagator in the region would experience.

The role of water vapor pressure plays a role during graft healing (Johnson and Miles, 2011). As temperatures increase throughout the day, warmer air permits a greater water-holding capacity and if the actual water vapor content in the area remains constant, the relative humidity will decrease as temperature increases. This can be seen in our data, particularly in the humidifier and plastic chamber, which had much higher relative humidity than the other treatments. Interestingly, the increased humidifier treatments seemed to consistently have lower afternoon temperatures compared with plastic treatments, although this trend was not statistically significant. This was probably because the cool-mist humidifier was actively cooling the chamber.

In addition to environmental control, another approach for lowering water stress in the scion is the removal of leaves to reduce transpiration within the scion tissue postgrafting. In our study, removal of scion leaves (LR) increased plant survival compared with standard controls $(P<$ $0.05)$, but removal of the apical meristem (SR) and leaves did not affect percent plant survival. The SR method did not provide a benefit as it relates to grafting success. However, it should be noted that grafting success was not penalized. Propagators who are looking to produce plants with two leaders (Rivard et al., 2010) would still benefit from this method as it could result in a finished product that is ready for market 10-14 d earlier than plants that are pruned in a similar manner postgrafting/healing.

One of the long-term goals of this work is to identify grafting methods that could be successful with limited propagation facilities. The ability to use shadecloth alone postgrafting could prove very beneficial to growers that do not have cooling equipment in their greenhouses as these chambers do not warm up during the day to the same extent as healing chambers that were covered with polyethylene films. It should be noted that no statistical interactions were seen between healing chamber design and grafting method. This indicates that the methods presented here would perform similarly in all the healing chamber microclimates that were evaluated. However, this could be the result of the optimum conditions of the greenhouse facilities, utilization of self-grafting, and the weather patterns that occurred during our experiments. The plants that were grafted in the standard manner and with no healing chamber had $91 \%$ and $81 \%$ success rates in Manhattan and at OHREC, respectively.

\section{Conclusions}

In this study, the effect of healing chamber design on environmental conditions as well as grafting success was tested. There were no significant effects of healing chamber design on 
grafting success, and grafts healed with no chamber had success rates of $81 \%$ to $91 \%$. Similarly, there was no effect of using a cool-mist humidifier, which is often recommended for small growers propagating their own plants (Rivard and Louws, 2011). Our data suggests that a humidifier is not necessary, and similar results were seen by Johnson and Miles (2011). The shadecloth treatment performed very well in this study and was also successful for tomato in the study reported by Johnson and Miles (2011). Growers may experiment with chamber modifications to reduce the risk of "overheating" in the greenhouse and this report provides valuable information related to the effects of chamber coverings on environmental conditions in two greenhouse environments.

Our findings related to grafting method will also provide insight for propagators who wish to experiment with variations of the tube-grafting or splice-grafting technique. The leaf LR method tested in our studies showed significant promise and plants grafted using this technique had significantly higher success rates as compared with standard- and SR-grafted plants $(P<$ 0.05 ). Leaf removal may be recommended as a way to reduce water stress in the plant, and could potentially be a way to simplify the grafting process for small-scale propagators.
Similarly, SR may be an effective method for propagators who are catering to growers that use vertical trellising systems that use plants with two leaders. A clear question for future research in this area is to determine how LR and/or SR affect the performance of mature plants in the field and/or greenhouse.

\section{Literature cited}

Bausher, M.B. 2013. Graft angle and its relationship to tomato plant survival. HortScience 48:34-36.

Besri, M. 2003. Tomato grafting as an alternative to methyl bromide in Morocco. 26 Mar. 2016. <http://mbao.org/2003/ $012 \% 20$ besrimgraftingmbao2003sd.pdf $>$.

Bumgarner, N.R. and M.D. Kleinhenz. 2014. Grafting guide: A pictorial guide to the cleft and splice graft methods. Ohio State Univ., Ohio Agr. Res. Dev. Ctr. Bul. 950 .

De Ruiter Seeds. 2006. Guidelines for grafting. De Ruiter Seeds, Bergschenhoek, The Netherlands.

Johnson, S.J. and C.A. Miles. 2011. Effect of healing chamber design on the survival of grafted eggplant, tomato, and watermelon. HortTechnology 21:752758 .

Kubota, C., M.A. McClure, N. KokalisBurelle, M.G. Bausher, and E.N. Rosskopf. 2008. Vegetable grafting: History, use, and current technology status in
North America. HortScience 43:16641669.

Lee, J.M. 1994. Cultivation of grafted vegetables: Current status, grafting methods, and benefits. HortScience 29:235-239.

Lee, J.M. 2003. Advances in vegetable grafting. Chron. Hort. 43:13-19.

Lee, S.G. 2007. Production of high quality vegetable seedling grafts. Acta Hort. 729:169-174.

Louws, F., C.L. Rivard, and C. Kubota. 2010. Grafting fruiting vegetables to manage soilborne pathogens, foliar pathogens, arthropods and weeds. Scientia Hort. 127:127-146.

Oda, M. 1995. New grafting methods for fruit-bearing vegetables in Japan. Jpn. Agr. Res. Qrtly. 29:187-194.

Oda, M. 2007. Vegetable seedling grafting in Japan. Acta Hort. 759:175-180.

Rivard, C.L. and F.J. Louws. 2011. Tomato grafting: A new tool for disease resistance and increased productivity. Sustainable Agr. Res. Educ. Ag Innovation Bul. Ser. SARE Publ. No. 12AGI2011.

Rivard, C.L., O. Sydorovych, S. O'Connell, M.M. Peet, and F.J. Louws. 2010. An economic analysis of two grafted transplant production systems in the U.S. HortTechnology 20:794-803.

Rivero, R.M., J.M. Ruiz, and L. Romero. 2003. Role of grafting in horticultural plants under stress conditions. Food Agr. Environ. 1:70-74. 